\title{
Wasted lives in scapegoat Britain: overlaps and departures between migration studies and disability studies
}

\begin{abstract}
The focus of this paper is to consider how disability studies and migration studies may be brought into further conversation with one another. While their experiences overlap and intersect in many ways, the lives of disabled people and migrants have rarely been considered together and this is an omission we attempt to-address in this paper as focusthrough a discussion on points of intersection and departure between migration studies and disability studies.

We argue that migrants and disabled people are among the most marginalised individuals today whilst a Global North neoliberal rhetoric has pushed them further to the margins. We draw on Bauman's (2016) theorisation of 'wasted lives' and-to bring disability studies and migration studies in dialogue with one another. Through this analysis, we highlight how bringing both disciplines together may help to inform debates focused on as they share a goal and both fight for social justice and rights to dignity for and-some of the world's most marginalised communities. '- rights to dignity.
\end{abstract}

Key words: disability, migration, social justice, minority rights, activism, neoliberalism

\section{Introduction}

Both disabled people and immigrants are subjected to similar scripts or repertoires of invalidation; to the same sneering language of abjection (Hughes, 2017, p. 12).

The focus of this paper is to consider how disability studies and migration studies may be brought into further conversation with one another to the benefit of both disabled people and migrants. Historically, disability studies have ignored the experiences of people who migrate, while migration studies frequently exclude disabled people (Hughes, 2017). This is a surprising omission from both fields of study given that many disabled people are migrants and many migrants are disabled people (Pisani \& Grech, 2015). 'The World Health Organisation (WHO) estimates that disabled people account for $7-10 \%$ of the world's population. This suggests that there are 4.4-6.2 million disabled people among the world's 65.3 million forcibly displaced persons' (Hughes, 2017, p. 1). However, reliable statistical data in relation to disabled migrants is in short supply.

By considering disability studies and migration studies together our aim is not simply to focus on the similarities and differences between people who identify as disabled and migrants. We want to avoid a reductionist approach that simply attempts to insert migration studies into disability studies or vice versa. Instead, we are interested in how the two areas of study intersect and how they can inform understandings of the social construction of the categories of 'migrant' and 'disabled person'. We want to consider mutual learning from their histories and their activisms as well as what insights this may bring for understanding lived experience. We want to join a conversation begun by Pisani and Grech (2015) in noting the absence of disability studies in migration studies, and continued by 
Hughes (2017) in his discussion of disability and migration and with a debt of thanks to Sherry (2004) whose work has informed our analysis. We build upon these debates by including the experiences of voluntary migrants as well as forced migrants into the discussion. While the latter received more attention (Yeo, 2017; Quinn, 2014; Roberts \& Harris, 2002), the former is largely ignored (Burns, 2017). We do this by looking at recent examples from the UK but acknowledge similar issues have been discussed in the Australian context (Soldatic \& Chapman, 2010).

We begin the paper by exploring the contemporary fast-changing and uncertain global context by drawing on Bauman's $(2016,2013)$ recent work on modernity and its outcasts. We discuss: the emergence of disability studies and migration studies; the social construction of disability and migration and how these intersect with one another; issues of passing and of disclosing identity status as disabled or migrant. This is followed by an exploration of how disabled people and migrants are constructed as passive and helpless. Finally, we acknowledge activist campaigns as acts of resistance. We conclude by arguing that both academics and activists involved in the politics of migration and disability can learn from each other and work together for social justice.

\section{The contemporary context: wasted lives in scapegoat Britain}

Disability affects us all, transcending class, nation and wealth (Goodley, 2011, p. 1).

As authors of this paper, we identify variously as dis/abled, non/migrant people. However, we are bound by our position of writing from the global North and from the very particular context of postBrexit-vote Britain. Yet, this paper has significance beyond the British context in a time of austerity, populism and disablism that sweep across Europe (Taylor, 2017) and the world (Klein, 2017). We are surrounded by evidence that demonstrates that the UK has undoubtedly benefited materially and culturally from its long history of immigration (Spencer, 1997). The UK has vibrant cultures and communities and is enriched by the participation of diverse people (Wood, Landry \& Bloomfield, 2006) and diverse skill sets (Blinder \& Allen, 2016). Despite this, it seems that many British people still struggle to accept the significant contribution that migrants and disabled people have made to the country (Craig, 2012). In a time of cuts to public services, there have been sustained attempts by successive governments to cast some members of the population as undesirable (them), in contrast with the hard working, independent, rational and economically active individuals who contribute to the neoliberal dream (us) (Stone, 1994). This context is becoming increasingly universal.

According to Naomi Klein (2017), global 'racial capitalism' has meant that ethnic minorities have wrongly become the scapegoats of practically any current crisis. We have seen that migrants have been increasingly cast as scapegoats - the cause of social and economic problems in the UK and as a drain on society (Barker, 2016). This narrative underpinned the campaign to leave the European Union by \#Brexit supporters and resulted in an increase in racially motivated hate crime immediately after the referendum result revealed that Britain have (by a narrow margin of 52:48) voted to leave the UK (Duda-Mikulin, 2019; Taylor, 2017). At the same time, disabled people have found themselves made vulnerable and scapegoats in austerity Britain (Quarmby, 2011). Stories of fraudulent, benefit scrounging disabled people have dominated the press and research suggests that there has been a concomitant rise in disability hate crime (Inclusion London, 2017). However, Sherry (2004) notes that hate crime against disabled people is not well documented. In neo-liberal-able times, disabled people and migrant people have become the objects of disavowal in contemporary 
British society (Goodley, Lawthom \& Runswick-Cole, 2014). As Hughes (2017, p. 11) writes: 'Brexit a political phenomenon that has invested heavily in cultural racism and ableism' is the latest manifestation of the neoliberal hegemony. Post-Brexit-vote Britain is characterised by a racialized discourse which somewhat validated racist rhetoric and has led to an unprecedented increase in hate crime (by $100 \%$ in some regions; Sharman \& Jones, 2017).

It is widely acknowledged that populism is a direct consequence of economic insecurity and austerity (Taylor, 2017). Populism reflects the uncertainty resulting from changing working practices in fast moving post-industrial economies which result in increased job insecurity. However, populism is more than a purely economic phenomenon. It is also a response to cultural change and an antiprogressive agenda which can be understood as a reaction to campaigns advocating for human rights, environmental protection, race, gender, migration equality and disability equality (Inglehart \& Norris, 2016). Populism depends on the production of such categories as 'disabled' and 'immigrant'.

The growing importance of free market capitalism, with limited involvement from the state, requires social actors to take the role of consumers who are in competition with one another and are only as valuable as their labour power (Monbiot, 2017). The structural inequalities that disadvantage disabled people and migrant communities are wilfully ignored or erased as the myth of the fairness of free market labour is constantly reproduced. Globally, the contemporary world is characterised by increased interconnectivity which leads to transnationalism with lesser significance of borders between nation states (International Organisation for Migration, 2010). Still, some individuals find it more difficult to move between countries. Those labelled as disabled people and migrants are often at the periphery of society, they are the 'hard-to-reach' or more accurately the 'easy-to-ignore' (Matthews, Netto \& Besemer, 2012). The categories of 'disabled' and 'migrant' are social constructs that are signified by a limited, or in some cases, total exclusion from the category of citizens.

In 2013, Bauman described the ways in which migrants, refugees and others have been produced as 'human waste or more correctly wasted humans (the 'excessive' and 'redundant that is the population of those who wither could not or were not wished to be recognized or allowed to stay)' (Bauman, 2013, p. 4). The waste of human life has been vividly represented on our television screens. 'Ghost ships' are sailing through the Mediterranean Sea with no crew but filled to the brim with vulnerable migrant people who are willing to put their lives at risk, and indeed die, in search of a safer life. On the other hand, disabled people with learning disabilities continue to die 13-20 years before their non-disabled peers (Mencap, 2007) while the unexpected deaths of people with learning disabilities are simply not investigated (Mazars Report, 2015).

Following Bauman's (1995) work on modernity and Hughes' (2002) analysis of it, 'the stranger' or 'the other' which was originally applied to ethnic minorities and migrants also applies to disabled people. This is while modernity is "a culture of forgetfulness, exclusion and confinement" (Hughes, 2002 , p. 572) which though familiar is threatened by the appearance of the stranger. 'The other' is equal to a dirt - "fear of the other or the stranger was based on the fear of incorporating impurity into the body" (Hughes, 2002, p. 574). This could be easily applied to both migrants who are increasingly believed to taint or contaminate the majority culture with their foreign customs and to disabled people who are often wrongly perceived to spread their illnesses onto others as if they were contagious. Indeed, "the strangers are believed to carry contagious diseases (...), disseminate moral depravity" (Bauman, 1995, p. 62) and thus they instil fear and resentment in the light of a lack of understanding and/or ignorance. Thus, through fear of the other, fear of the different, the 
stranger should be confined and "difference is to be severed or corrected, exiled or normalised" (Hughes, 2002, p. 575). This solution however, is unachievable with regards to disabled people or migrants as their differences cannot be eliminated. They can though be made familiar through education, contact, interaction, curiosity and sensitivity in approach.

Because 'us' is in opposition to the strangers, the normal is perceived to be in opposition to the abnormal, the familiar is acquainted and thus does not carry fear with it, whereas the strange brings with it a fear of "contamination from the impurities that strangers are thought to embody" (Hughes, 2002 , p. 577). As post-modernity is a 'visual culture', the preference is for physical and mental perfection and whilst differences are often celebrated, this still does not happen frequently in relation to disabled or migrant people.

In modernised societies, migrants and disabled people seem, too often, to have been abandoned to the category of human waste (Bauman, 2013). 'Migration crisis' was invented in order to remove emphasis from the states failing their people and instead focus on what later became a 'migration panic', a convenient scapegoat (Bauman, 2016). As Bauman argues, migration is an age-old strategy to improve life but 'our modern way of life includes the production of redundant people (locally inutile - excessive and unemployable - due to economic progress, or locally intolerable - rejected as a result of unrest, conflicts and strife caused by social/political transformations and subsequent power struggles)' (ibid. p. 3). We argue that the category of wasted humans applies to both disabled people and migrants. While their experiences overlap and intersect in many ways, as we see below, and as we argued above, disabled people and migrants have rarely been considered together (Hughes, 2017; Pisani \& Grech, 2015), and this is an omission we will attempt to address here. We begin by considering the histories of migration studies and disability studies.

\section{The emergence of disability studies and migration studies and a note on definitions}

Although we are aware of the well-informed readership of the Journal we wish to sum up the historical emergence of disability studies. Disability Studies is a relatively new discipline. Indeed, before the 1990s, medicine and psychology were the usual disciplinary home for discussion of disability (Barnes, 2008). Back in the 1940s, managing health and illness was a key concern for the medical sociologist Talcott Parsons (1951). He argued that 'the sick' and 'the disabled' could be excused from work or contributing to family life, but, crucially, only if they accepted 'the sick role', which required people to follow doctor's orders and to try to 'get better' (Mallett \& Runswick-Cole, 2014).

The rise of the Disabled People's Movement can be traced to the formation of the National League of the Blind in the 1890s. It was not the shared experience of impairment that led them to organise, rather what united them was a perception that their marginalisation within society depended on the benevolence of others. Allied to this, the group objected to the fact that many of the organisations who purported to lobby on behalf of those with physical impairments were controlled by nondisabled individuals (Adams, Reiss \& Serlin, 2015). The goals of economic security, civil rights and independence were for the league inextricably linked and fundamental to the struggle of disabled people in society.

The category 'disability', according to Russell and Malhotra (2002), is a capitalist creation used to define a group of people who are unable to work and as a consequence the Disabled People's 
Movement was created in order to reclaim control and realise aspirations. The cornerstone of the Disabled People's Movement challenged the social culture that denies disabled people the right to self-determination. They defied the widely held assumption that disability was primarily biologically determined. Instead, the Movement presented a new conception of disability as a social construct and consequently it is something that can be eliminated.

In 1960s there were challenges to traditional approaches to disability which continue to inform contemporary approaches in Disability Studies. The sociologist, Erving Goffman (1963) began to examine the stigma associated with disability. Disabled people, most notably Paul Hunt, in his book Stigma: The Experience of Disability took up these ideas and today many academics working in Disability Studies are disabled people. This has had a welcome effect of blurring the distinction between the researcher and the researched and academia and activism (Runswick-Cole, 2016).

A defining moment in British Disability Studies made by disabled people is the work of the Union of the Physically Impaired Against Segregation (UPIAS), a group of people with physical and sensory impairments. Activists began to make connections between the struggle of Black South Africans for emancipation and disabled people's struggles for equality (Shakespeare, 2006).

By 1976 UPIAS published Fundamental Principles of Disability, in which it stated that its members' struggle was developed from a social theory of disability. UPIAS (1976 cited in Oliver 1996:25) defined disability as opposed to impairment as follows:

we define impairment as lacking part of or all or of a limb, organ or having a defective limb, organ or mechanism of the body; and disability as the disadvantage or restriction of activity caused by a contemporary social organisation which takes no or little account of people who have physical impairments and thus excludes them from the mainstream of social activities. Physical disability is therefore a particular form of oppression.

Simultaneously, Disability Studies was developing as an academic subject. In 1975, the Open University introduced a course entitled 'The Handicapped Person in the Community'. This was the first undergraduate course in Disability Studies in the United Kingdom. In 1986, the international journal Disability, Handicap and Society (in 1993 renamed Disability and Society) was published and the discipline began to attract more attention. By 1990, Mike Oliver published The Politics of Disablement, which has been described as the first comprehensive account of the socio-political interpretation of disability (Barnes, 2008). Oliver offers a Marxist materialist account of the oppression of disabled people known as the social model of disability.

More recently, Critical Disability Studies have developed from the field (Mallett \& Runswick-Cole, 2014). As Goodley (2013, p. 632) tells us, 'critical disability studies start with disability but never end with it: disability is the space from which to think through a host of political, theoretical and practical issues that are relevant to all.' Crucially, Critical Disability Studies approaches do not seek to abandon social oppression approaches to disability but seek to engage with a range of resources (from feminist to queer thinkers, among others) (Mallett \& Runswick-Cole, 2014). Critical Disability Studies is, then, well placed to open up a dialogue with Migration Studies.

Moving onto Migration Studies; migration is an ageless strategy to improve one's life and humans have migrated since the beginning of time. However, it was only relatively recently, in the $18^{\text {th }}$ and $19^{\text {th }}$ centuries, that the phenomenon of migration was problematised and migrants began to be seen as distinctive objects of scrutiny and study (Gabaccia, 2014). Ravenstein (1885) first coined the laws of migration', since then geographers and others have followed and have sought to explain this process. 
The Chicago School of Sociology is said to be the first to study migration systematically. This name refers to the University of Chicago and their academics' pioneering work within the area of urban sociology undertaken in the first half of the $20^{\text {th }}$ century. Among the Chicago School scholars were an American sociologist William I. Thomas and a Polish sociologist Florian Znaniecki who in 1918 authored The Polish Peasant in Europe and America. Thomas together with another Chicago School academic Louis Wirth, began research which in 1928 led to an important publication in urban ethnic studies, The Ghetto. These two works, The Polish Peasant in Europe and America together with The Ghetto became the cornerstones of Chicago School work on immigration (ibid.). This work is thought to give rise to the discipline of Migration Studies as we know it today.

Since the 1980s, Migration Studies has become an increasingly more popular field of study which was no doubt stimulated by a substantial rise in people seeking asylum and refuge due to various conflicts that occurred around that time. Yet, Refugee and Forced Migration Studies is largely a separate area of academic enquiry which is said to emerge during the 1980 s when academic journals (e.g. Journal of Refugee Studies) and research and teaching centres (e.g. the Refugee Studies Programme at the University of Oxford) were established (Fiddian-Qasmiyeh et al., 2014). Interest in refugee movements predates the emergence of the discipline and was studied during the interwar and post-Second World War periods (ibid.). As shown above, Migration Studies is not a unified discipline. The complexity around classifications resulted in several distinct subfields, including: Migration Studies, Transnational Migration Studies and Refugee Studies which is sometimes termed Forced Migration Studies.

Migration can be divided into international movements and those within the boundaries of one nation state but it is the former that often occupies political, media and public debates. Some scholars postulate that the boundaries between forced and economic migration have become blurred (Castles \& Van Hear, 2005). Castles and Miller (2009) argue that we now live in the 'age of migration' that is characterised by the acceleration, increasing fluidity and unpredictability of international movements. Migration is one of the key processes of social change and development (Klagge et al., 2007) and is increasingly understood as a process rather than a one-off event (Pemberton \& Scullion, 2013). More recent literature recognises people's 'mobility' as more relevant than 'migration' as it signifies fluidity and blurring between its various types and a greater unpredictability of individuals' mobility patterns (O'Reilly, 2009). However, according to some scholars, "the mobility turn" in social sciences emphasises the divide between the largely unwanted migration of labour migrants and the more positively perceived mobility of highly-skilled professionals (Faist, 2013). Refugees and asylum seekers do not feature in this categorisation as they belong to the asylum system. This signifies another complication to the hierarchy of migrants defined as those who cross international borders.

Both disciplines, migration studies and disability studies, are relatively new disciplines that aim to fight marginalisation and raise the voice of those who are too easily silenced emphasising the social construction of these categories whereby society is to be blamed for relative disadvantage and exclusion of migrants and disabled people. Both disciplines try to challenge the societal approach towards people who are migrants and disabled people as those who are the victims of scapegoating whilst their personal circumstances are rarely in their control. What we learn from this shared/divergent history of the emergence of the disciplines is that both fields have been led by scholars who could be termed as activists as they assume those labels and identities as disabled (see 
e.g. Crow, 2009; Shakespeare, 2006) and migrant people (see e.g. Nowicka \& Ryan, 2015; DudaMikulin, 2014; Romocea, 2014). We postulate that the two disciplines, Migration Studies and Disability Studies, are fighting the same fight for social justice and thus are subjected to similar scenarios of validation. Therefore, it is worth bringing them into a conversation with one another. We now move on to discuss disabled and migrant people's identities.

\section{Migrant and disabled people as a minority group and guesstimations}

Linton (1998, p. 12) notes that: 'disability is best understood as a marker of identity (...) incorporating people with a range of physical, emotional, sensory, and cognitive conditions. Although the category is broad, the term is used to designate a specific minority group'. In that respect, both migrants and disabled people can be identified as a minority group and both designate a marker of identity. Both terms are slippery and their definition will vary depending on cultural, geographical, political and theoretical orientation of the person offering a definition.

$21 \%$ of the UK population reported to have a disability in 2015/16. It is estimated that there are 13.3 million disabled people in the UK (DWP, 2016). Only 17\% of disabled people were born disabled. The majority of disabled people develop an impairment or disability later in life (Papworth Trust, 2016). Around $7 \%$ of children are disabled, compared to $18 \%$ of working age adults and $44 \%$ of adults over State Pension age (DWP, 2016).

According to estimates, in 2015 13.5\% of the UK population was foreign-born and 8.9\% comprised non-British citizens. 'The share of foreign-born people in the UK's total population increased by more than half between 1993 and 2015, i.e. from 7\% to nearly 13.5\%. During the same period, the share of foreign citizens in the UK's population rose from $3.6 \%$ to $8.9 \%$, while that of recent migrants increased from 1.3\% to 3.2\%' (Vargas-Silva \& Rienzo, 2017). This statistical data will however depend on how a migrant is defined and there are various ways of classification as asserted above (Anderson \& Blinder, 2017).

It is difficult to estimate the proportion of migrants who are disabled. According to the European Union Agency for Fundamental Rights, persons with disabilities make up around 15\% of the global population and comprise a significant minority of refugees and migrants (FRA, 2016). Using statistical data from 2017, Hughes (2017) estimated that there are four to six million disabled migrants. The Papworth Trust released data in relation to prevalence of disability by ethnic group, according to which disabled people account for 1 in 4 Black/African adults; 1 in 5 White adults; 1 in 6 Hispanic adults; and 1 in 10 Asian adults (Papworth Trust, 2018).

Yet, it is uncommon to include disabled people among those who are considered as particularly vulnerable in disasters and displacement and thus may require targeted response (Forced Migration Review, 2010). The European Union Agency for Fundamental Rights (FRA, 2016) states that: 'there is a lack of formal procedures to identify migrants and refugees with disabilities (...). This can have significant knock-on effects for the provision of targeted support and assistance'. FRA also acknowledged the lack of statistics in relation to disabled people among new entrants and the breakdown per type of disability. This means that disabled migrants may come off the radar and be invisible as a minority group (as White, for instance), and invisible as their potential disability is not taken into account. The lack of data on the scale and complexity of this problem will likely result in 
migrants and disabled people not being able to access adequate support. This is why we feel it necessary to explore and draw upon both disability studies and migration studies in order to highlight some of the most disadvantaged communities.

'Non-white races were routinely connected to people with disabilities, both of whom were depicted as evolutionary laggards or throwbacks' (Baynton, 2001, p. 36). Historically, racism and ableism have prevented ethnic minorities from full participation in society and they are still in play today (Goodley, 2011). In 2014, The UN High Commissioner for Refugees (UNHCR) reported that the number of people displaced by bloody conflict and persecution had exceeded 50 million for the first time since World War II (Lewis, 2014). Contemporary conflicts in Syria and other nations are exacerbating the problems of displacement; and we know from the 2011 World Report on Disability by the WHO that where there is conflict, poverty and displacement then there is often disability (Pisani \& Grech, 2015). Whilst this section looked at how migrant and disabled people belong to minority groups, the next section considers issues around disclosing aspects of identity.

\section{Passing, disclosure and coming out}

Sherry (2004) describes the ways in which Disability Studies and Queer Theory have engaged in discussions of 'passing' or 'coming out'. He notes the ways in which discussion of 'passing' as nondisabled or 'outing' oneself as a disabled person have usually focused on 'non-visibly impaired people' (ibid. p. 273). The idea circulates that people with non-visible impairments can choose to pass while those visibly impaired cannot (Ahmed et al., 2015). Similarly, it is perceived to be easier for some migrants to 'pass' as non-migrant people, this is linked to markers of ethnicity and origin and the visibility of these in relation to the majority population. Again, the requirement to pass or the decision to disclose, or not, places a burden on migrants. Yet, public disclosure of undocumented status can be a political act and in itself challenge the societal exclusion, invisibility, and dehumanisation of people who are termed undocumented migrants (Galindo, 2012). Additionally, those who are 'undocumented' are often referred to as illegal entrants or simply illegals; and whilst the worldwide campaign 'No Human Being Is Illegal' (Gambino, 2015) argued against using this derogatory and misleading term, it is still in common use particularly by immigration officials. Migrant 'illegality' has risen to 'unprecedented prominence as a 'problem' in policy debates and as an object of border policing strategies for states around the world' (De Genova, 2002, p. 419) but it mislabels migrants. Forced migrants often do not have a choice but to flee their homes due to conflicts they often have no part in while the label 'illegal' or 'undocumented' further exacerbates their exclusion from nation states.

While disabled people and migrant people sometimes may be able to pass as non-disabled or nonmigrant, at other times society requires that people perform the role of 'disabled person' or 'migrant'. This performance is usually tied to the requirements of the social welfare system and other sources of support for community living. Butler's (1990) notions of 'performance' and 'performativity' are useful here. For Butler, gender is a performance during which the individual in question needs to convince others around them that they are who they claim to be. Both migrants and disabled people experience requirements to perform their roles - they must convince those around them that they are entitled to support and/or eligible to enter a country. 
For disabled people, this requirement to perform manifests itself in numerous ways, but the performance carries special significance when disabled people are subjected to the rigours of fitness to work tests and assessments before they are entitled to financial benefits. The Work Capability Assessment (WCA), for example, introduced in the UK as part of Employment and Support Allowance (ESA) in 2008 and continuing as part of Universal Credit requires disabled people to perform certain types of embodiment if they are to receive financial support from the state. Access to the disability components of social security is limited to those whose performance of 'disability' can be codified in the context of a medicalised, functional assessment. Those who fail to perform disability in the ways recognised by the assessors, including those with mental health issues, fluctuating impairments and learning disabilities, become vulnerable in a system which fails to recognise their experiences as an adequate performance of disability (McNeill et al., 2017). Furthermore, eligibility and status can change overnight with changes in policy. For example, the redrawing of the 'disability category' with the introduction of ESA meant that for some people, 'administrative health status changed overnight, despite no actual change in their health state' (Garthwaite et al., 2014, p. 328).

Similarly, people who are migrants are constantly scrutinised about their status and eligibility (Lewis et al., 2014). They are expected to convincingly perform migrant status but not all are deemed as 'deserving' as others. The relatively recent story of a young man from the now dismantled 'Jungle' in Calais, France, who sought refuge in the UK as a minor but his age was put to question is one example (Express, 2016). Following these claims, security checks at UK borders were hardened verifying people's age and identity in order to make sure only the most 'deserving' and those convincingly passing as genuine refugees are granted entry.

Migrants have to demonstrate eligibility not just to enter the country but to access rights once within the UK (Cook, Dwyer \& Waite, 2012). From the end of 2013 the British authorities introduced measures that imposed gradually more restrictive access to welfare for European Economic Area (EEA) nationals, for instance. In 2013, a more robust Habitual Residence Test was announced for means-tested benefits claimants. From 2014, income-based Jobseeker's Allowance (JSA) claimants had to have resided in the UK for a minimum of three months to have their claims approved. A minimum earnings threshold was also introduced to decide if a person was in 'genuine and effective' work, and thus had a 'right to reside' in the UK, which appears to have been continued under Universal Credit. Additionally, jobseekers have to demonstrate that they have a Genuine Prospect of Work (GPoW). This requires individuals to provide 'compelling evidence' that they are actively seeking work and have a genuine prospect of finding work. However, recent research has demonstrated that meeting these requirements has proven to be an 'additional unsurmountable barrier for many migrants, even those who had long histories of residence and paid employment in the UK' (Dwyer et al., 2019). These additional requirements have become an integral element of the complex and highly conditional 'activationist-plus' welfare regime within the UK, but also across a number of other EU Member States (O'Brien, 2013, 2016). Moreover, from July 2014 new jobseekers need to have lived in the UK for three months before being entitled to Child Benefit or Child Tax Credit (Kennedy, 2014). Migrants from outside the EEA (i.e. Third Country Nationals) to the UK are subject to a 5-tier points-based immigration system when they wish to come to the UK to work, study, invest or train. In order to be eligible for a visa in any of the tiers one must pass a points-based assessment. The tiers group migrants into exceptional talent, investors, entrepreneurs, temporary workers and youth mobility, among others. In work visa applications, points are generally awarded according to the applicant's ability, experience and age, with a narrative of allowing entry 
to the UK to only the 'brightest and best' (Green, 2012). As we have shown above, matters of passing are complex while disclosure is often necessary when one wishes to qualify for support from the state or be granted entry. We now move on to discuss the ways in which migrants and disabled people are represented in public discourse and the media.

\section{Passive state welfare recipients subject to discrimination, exclusion and stigma}

In his recent paper, Hughes (2017) argues that disabled people and migrants are subject to similar forms of representation; yet confirms that the two concepts have not been often considered together. Hughes emphasises ethnocentric and ableist preconceptions that pull disability and migration together. He notes that in present-day Britain both disabled people and migrants are represented as 'idle and morally disreputable' (Hughes, 2017, p. 1), 'conceived as social outliers' (p. 4) and that they are 'among the most invisible' (p. 2). This, then, begs the question whether ableism and racism constitute double disadvantage or intersect one another producing a truly unique and multifaceted experience of exclusion. Arguably, disabled migrants are subject to double marginalisation and double disadvantage. The two 'isms', ableism and racism, which signify intersecting axes of difference based on dis/ability and ethnicity/origin, affect the lives of those who identify as such. Disabled migrants are often perceived as passive recipients of help and thus a liability to any nation state or its economy (Forced Migration Review, 2010; Yeo, 2017). They have become unwanted wasted humans (Bauman, 2013) as few volunteer to provide them with shelter while the responsibility is often passed from pillar to post.

'It is difficult to resist the evidence that (cultural) racism is globally in the ascendancy. Equally, it is difficult to resist the argument that racism and disablism are bedfellows that feed from one another' (Hughes, 2002, p. 581). While modernity could be seen as actively involved in 'the social production and reproduction of the immorality of indifference' (Hughes, 2002, p. 581), the terms im/migrant and disabled are characterised by negative connotations and have arguably become dirty words. 'The invalidating practices of modernity are derived from a narrow, attenuated sense of inclusiveness in which anything or anyone 'out of the ordinary' has to be assimilated or banished' (Hughes, 2002, p. 582). These lead to numbness and exclusion.

It can be asserted that disabled people have always, to an extent, been perceived as passive recipients of help and as those who need support (Hughes, 2017). Still, many disabled people live independent lives and campaign to overcome the reductionist view of disabled people as incapable of looking after themselves (Liddiard, 2018). It is true that some disabled people's health needs may prevent them from being fully independent but they should not be reduced to their disability.

Those seeking asylum are increasingly portrayed as passive recipients of help rather than what they are - people in need of shelter and protection due to compelling humanitarian reasons. More recently, emphasis has shifted from compassion and charity to deservedness and stone-cold economic calculation. Because of this, support for humanitarian causes has decreased. Indeed, at the height of debates during the 1990s around the growing number of asylum seekers coming to the UK, a new 'threat' was identified in the shape of the 'undeserving' or 'bogus' asylum seekers who were no longer to be regarded as 'genuine' refugees, but disguised 'economic migrants' whose claims for asylum were 'simply a tissue of lies' (UK Home Office, 1998, Paragraph 1.14). In more recent years, attention has shifted to the arrival of large numbers of Central and Eastern European 
migrants to the UK. Their arrival has been met with political and public debate around the need to curtail migration due to perceived impacts on indigenous labour market opportunities coupled with fears about the demands placed on the UK welfare system (Cook, Dwyer and Waite, 2012), including a 'benefit tourism' narrative applied to some migrant communities e.g. Roma (Martin, Scullion \& Brown, 2017).

Historical exclusion and discrimination of disabled people from access to education, employment and housing is well acknowledged (Goodley, 2011). More recently, with widespread austerity in the UK, disabled people are among the hardest hit communities (Bates, Goodley \& Runswick-Cole, 2017). Also, increasingly open hostility towards migrants has been recorded following the Brexit vote in the UK (Duda-Mikulin, 2019; Sharman \& Jones, 2017) and the election of Trump for President in the US. Both of those events validated the feeling of resentment towards outsiders and others who are different than us. As illustrated, this is not only characteristic of the UK but the US and the increasingly globalised world.

The theory of abjection (Hughes, 2009) provides another point at which Disability Studies and Migration Studies intersect and share commonalities. The abject is disturbing for any existing order (e.g. identity, system). 'The abject constitutes a threat to life, to identity and order' (ibid., p. 405). It causes offence, threatens to cause the breakdown of existing norms and coherence of normality. Hence, the theory of abjection can be applied to both disabled and migrant people as those who are perceived to disrupt the normative. 'Othering' and abjection invalidate certain categories of people by constructing them as threats and strangers as Hughes $(2009,2002)$ convincingly argues.

Disabled people are often considered an economic burden on the welfare system, which results in their exclusion and marginalisation in the migration process. Indeed, the UK Chancellor of the Exchequer, Philip Hammond, recently blamed disabled workers for the slow growth of the UK economy (Kentish, 2017). Immigration policies, such as those of Canada and the UK, provide examples of the institutionalisation of neo-colonialism in their overemphasis on the economic suitability of potential migrants, thereby reinforcing a historical tendency of the North to profit at the expense of the South. The point-based system and selection process are constructed in ways that deny disabled people entry as migrants. The emphasis is on education and employment, areas from which migrants, as well as disabled people, have typically been excluded (El-Lahib \& Wehbi, 2011).

Migration can be seen as a key aspect of social transformation in society and an inevitable consequence of globalisation (Castles, 2010). The number of migrants worldwide has increased and diversified to such an extent that Vertovec (2007) describes it as an age of 'superdiversity'. It can be said that the increasing global connectedness renders mobility inevitable. Yet, many countries construct migration and certain types of migrants as a problem and seek ways to mitigate it. The immigration law in the UK requires (non-EU, for now) migrants who wish to bring their family over to be in receipt of a minimum income of $£ 18,600$ (Gov.uk). This requirement will affect disabled people and their families, given that families with a disabled member often have lower household income (Bates, Goodley \& Runswick-Cole, 2017). While we can point to the ways in which migration policy seeks to exclude disabled people, disabled migrants are a hidden population (Hughes, 2017; Pisani \& Grech, 2015). Disabled migrants' views and the factors which shape their experiences of the migration process and their lives in their new countries are unclear. However, the intersection of structural forces such as socioeconomic inequalities, racism, sexism and disablism in the lives of 
migrants has begun to be explored in disability studies (Yeo, 2017; Soldatic et al., 2015; Roberts \& Harris, 2002).

It is noteworthy that recent years have seen a rise in popularity of reality television shows. Among these are shows that focus on the portrayal of some of the most vulnerable and disadvantaged communities. In the UK, programmes such as Benefits Street, Gypsies on Benefits and Proud and Immigration Street, for instance, present a similar socio-cultural construction of categories of diversity that are exposed to and scrutinised by the general public who decide whether they do or do not qualify as 'scroungers' and consequently how deserving they are. The mentioned programmes were publicised as a documentary series. Both Benefits Street and Immigration Street proved controversial and the broadcaster Channel 4 faced scrutiny and criticism (Burrell, 2014). The 'stars' of the shows often felt demonised and misrepresented and the local residents actively opposed Love Production, the producer of the series, from filming. Perhaps precisely because of the controversial themes being portrayed, Benefits Street attracted more than five million viewers and close to two thousand complaints to the Office of Communications but it was cleared of breaching broadcasting rules (Khaleeli, 2015). The TV series On Benefits and Proud broadcast on Channel 5 in the UK was termed as the 'show where deserving taxpayers stalk proud benefit claimants' which is 'televisual gold' as 'there is something particularly brilliant about the poor' (Ryan, 2013). Ryan termed this a 'banal anti-benefit propaganda' and the 'opportunity for scapegoating' (ibid.). The following penultimate section is a discussion of activism for social justice.

\section{Acts of resistance}

We recognise that there have been several successful campaigns fighting for social justice of migrants (see Espinosa, 2014) and disabled people (see Soldatic \& Chapman, 2010). Still, these have been largely separate in their efforts but The3million campaign in the UK has recently recognised the distinctive needs of disabled EU migrants.

Historically, the Disabled People's movement was concerned with the emancipation of disabled people. However, with the onset of austerity it is arguable that the focus of the movement is now one of resistance and survival. The campaign Justice for the Laughing Boy is noteworthy (the Justice for LB, see http://justiceforlb.org/). The Laughing Boy was Connor Sparrowhawk and his mistreatment and tragic death have led to new forms of disability activism. Such activists-led campaigns utilise the power of social media to highlight injustice. Interestingly, Justice for $L B$ campaign included disabled people, their family members and their allies. This can be seen as a departure from traditional forms of disability activism based upon self-identity as a disabled person. The use of social media and blogs in the Justice for $L B$ campaign resulted in improving the treatment of those with learning disabilities who reside within institutions (Ryan 2017). In March 2018, five years after Connor Sparrowhawk's death, Southern Health NHS Foundation Trust has been fined a record amount, two million pounds, for what was termed a systemic failing.

Campaigns such as The3million (see https://www.the3million.org.uk/) and British in Europe (see https://britishineurope.org/) are worth mentioning as they currently play a vital part in lobbying the government to secure the rights of EU migrants in the UK and British migrants (often favourably termed expatriates) within the EU. The situation of disabled EU migrants is particularly complex (Huijg, 2018). The3million was launched to bring awareness to the extreme difficulties that EU 
citizens and their families are facing in light of Brexit with regards to their rights and entitlements and legally regulating their stay in the UK post Brexit. From their website we learn that the most vulnerable, including disabled migrants are frequently unable to legally secure their stay in anticipation of Brexit. Whilst The3million operates from the UK with the focus on EU citizens' rights, British in Europe is based on the continent and raises awareness of British citizens in Europe.

Despite the abovementioned campaigns which raise the voice of those who are so often silenced more needs to be done to spread awareness of the complex needs of disabled people, migrants and disabled migrants and their multifaceted disadvantage. For this very reason we write the current paper in the hope that it will advance the understanding of the impact of popular discourses in the media, policy and practice related to some of the most marginalised communities, migrants, disabled people and disabled migrants, and the damage they are causing to real people's lives while joint efforts between Disability Studies and Migration Studies would no doubt help redress some issues that are faced.

\section{Conclusion}

As we attempted to show the complexity of experience for those of us who identify as migrants or disabled; this is by no means a comprehensive account. Rather, we hope that this paper will serve as a starting point for a more inclusive and wide-ranging debate around the socially constructed categories that disadvantage their bearers. Migrants, disabled people and disabled migrants are among the most marginalised individuals today whilst the neoliberal rhetoric, Brexit in the UK and Trump in the US has criminalised their lives. Thus, Bauman's (2016) assertion of 'wasted lives' is particularly appropriate. We argue that we need to reconstruct the meanings of the labels 'disabled' and 'migrant' and reconsider the ways in which we approach these topics. Our aim is to bring closer two scholarly disciplines, Disability Studies and Migration Studies, which share a goal for social justice and some of the most marginalised communities' rights to dignity. As academics from these two distinct disciplines we came together to write this paper and debate the situation of disabled and migrant people and disabled migrants.

Migrants and disabled people are socially constructed labels that are misleading and the current meanings attached to them are simply wrong. They both depict invisible populations which need to be elevated to a national concern, not as a burden and 'wasted humans' but as equal human beings who contribute and deserve recognition in their relative disadvantage. These categories dehumanise their bearers and this misrepresentation of disabled people and migrants requires a counter narrative to popular news stories that depict them in a negative light as a drain and liability. As scholar activists we need to stress positive voices, stories and depictions as a form of positive action to counterbalance existing discrimination. As those who have often been excluded and lack a voice, migrants and disabled people are easy scapegoats and convenient victims to be blamed for current crises: economic, humanitarian. The historical marginalisation, exclusion and stigma needs to be overcome and this paper aims to serve as a starting point for debates on disabled migrants and repositioning them from 'wasted lives' into 'us' whilst 'them' should be understood as those who refuse to recognise equality and dignity in practice, policy and popular discourse.

By writing this paper we aim to contribute to bridging the gap between Migration Studies and Disability Studies which our colleagues Pisani and Grech (2015) identified and Hughes (2017) also 
previously discussed. We provide a counter narrative to more common voices depicting disabled people and migrants in a negative light and emphasise the social construction of these categories. However, we acknowledge that this paper is grounded in theoretical context whilst more empirical research on the lived experience of these matters and their role in shaping disabled and migrant identities is needed.

Word count: 7718

Acknowledgements

$\mathrm{xxx}$ 


\section{References}

Adams, R., Reiss, B. \& Serlin, D. (2015). Keywords for Disability Studies. New York: New York University Press.

Ahmed, T., Hoyle, R., Connelly, K., Crandall, D. \& Kapadia, A. (2015). Privacy Concerns and Behaviors of People with Visual Impairments. CHI '15 Proceedings of the 33rd Annual ACM Conference on Human Factors in Computing Systems.

Anderson B. \& Blinder, S. (2017). Who Counts as a Migrant? Definitions and their Consequences. Oxford Migration Observatory. Available from: http://www.migrationobservatory.ox.ac.uk/resources/briefings/who-counts-as-a-migrantdefinitions-and-their-consequences/

Barker, R. (2016) How foreigners became the convenient scapegoat of the referendum campaign. LSE Blogs: British Politics and Society, 26th June.

Bates, K., Goodley, D. \& Runswick-Cole, K. (2017). Precarious lives and resistant possibilities: the labour of people with learning disabilities in times of austerity. Disability \& Society, 32(2), pp. 160175. doi: 10.1080/09687599.2017.1281105.

Bauman, Z. (1995). Life in Fragments: essays in postmodern morality. Oxford: Blackwell.

Bauman, Z. (2016). Strangers at our door. Cambridge: Polity Press.

Bauman, Z. (2013). Wasted Lives: modernity and its outcasts. Cambridge: Wiley.

Baynton, D. (2001). "Disability and the Justification of Inequality in American History." In The New The New Disability History, edited by P. Longmore and L. Umansky, 33-57.

Blinder, S. \& Allen, W. (2016). BRIEFING. UK Public Opinion toward Immigration: Overall Attitudes and Level of Concern http://www.migrationobservatory.ox.ac.uk/wpcontent/uploads/2016/04/Briefing-Public Opinion Immigration Attitudes Concern.pdf

Burns, N. (2017). The human right to health: exploring disability, migration and health, Disability \& Society, 32:10, 1463-1484, DOI: 10.1080/09687599.2017.1358604

Burrell, I. (2014). 'Benefits Street': Channel 4 documentary sparks anger and threats of violence http://www.independent.co.uk/news/media/tv-radio/channel-4s-benefits-street-sparks-anger-andthreats-of-violence-9044880.html

Cook, J., Dwyer, P. \& Waite, L. (2012) 'Accession 8 migration and the proactive and defensive engagement of social citizenship', Journal of Social Policy, 41(2): 329-347.

Craig, G. (2012). The history and pattern of settlement of the UK's black and minority ethnic population. In G. Craig, K. Atkin, S. Chattoo, \& R. Flynn, Understanding 'race' and ethnicity: theory, history, policy, practice, (pp. 41-69). Bristol: The Policy Press.

Crow, L. (2009). Ouch! It's a disability thing. 13 Questions: Liz Crow. BBC, 24th November.

De Genova, N. (2013). Spectacles of migrant 'illegality': the scene of exclusion, the obscene of inclusion. Ethnic and Racial Studies, 36(7), pp. 1180-1198, doi: 10.1080/01419870.2013.783710. 
Duda-Mikulin, E.A. (2019). EU migrant workers, Brexit and precarity. Polish women's perspectives from inside the UK. Bristol: Policy Press

Duda-Mikulin, E.A. (2014). Interviewing Polish Migrant Women in the United Kingdom and Poland. In SAGE Research Methods Cases. London, United Kingdom: SAGE Publications, Ltd. doi: $10.4135 / 978144627305014529524$.

Department for Work and Pentions (2016). Family Resources Survey 2015/2016 www.gov.uk/government/uploads/system/uploads/attachment data/file/600465/family-resourcessurvey-2015-16.pdf

Dwyer, P., Scullion, L., Jones, K. and Stewart, A.B (2019) 'The Impact of Conditionality on the Welfare Rights of EU Migrants in the UK', Policy \& Politics, 47(1): 133-150.

El-Lahib \& Wehbi (2011). Immigration and disability: Ableismin the policies of the Canadian state. International Social Work, 55(1), pp: 95-108. doi.org/10.1177/0020872811407941.

Espinosa, S.A. (2014). From International Solidarity to Migrant Activism: Critical Junctures in Philippine-Australian History. Social Movement Studies, 13(4), pp. 499-513. dOI: 10.1080/14742837.2013.865514

European Union Agency for Fundamental Rights (FRA) (2016). Fundamental Rights Report 2016. Available from: http://fra.europa.eu/en/publication/2016/fundamental-rights-report-2016

Fiddian-Qasmiyeh E., Loescher G., Long K. \& Sigona N. (2014). Introduction in Refugee and forced migration studies. Oxford University Press

Forced Migration Review (2010). Disability and displacement. Available from: http://www.fmreview.org/disability.html

FRA (2016). European Union Agency for Fundamental Rights. Thematic focus: Migrants with disabilities. Available from: https://fra.europa.eu/en/theme/asylum-migrationborders/overviews/focus-disability

Gabaccia D.R. (2014). Time and Temporality in Migration Studies. In C.B. Brettell and J.F. Hollifield (eds.) Migration Theory - talking across disciplines. 10.4324/9781315814933

Galindo, R. (2012). Undocumented \& Unafraid: The DREAM Act 5 and the Public Disclosure of Undocumented Status as a Political Act. Urban Review, 44(589). https://doi.org/10.1007/s11256012-0219-0

Gambino, L. (2015). 'No human being is illegal': linguists argue against mislabeling of immigrants. The Guardian, 6th December.

Garthwaite, K., Bambra, C., Warren, J., Kasim, A. \& Greig, G. (2014). Shifting the goalposts: a longitudinal mixed-methods study of the health of long-term incapacity benefit recipients during a period of substantial change to the UK social security system. Journal of Social Policy, 43(2), pp. 311330.

Goffman, E. (1963). Stigma. London: Penguin. 
Goodley, D. (2011). Disability Studies: An Interdisciplinary Introduction. London: SAGE Publications Ltd.

Goodley, D., Lawthom, R. \& Runswick-Cole, K. (2014). Dis/ability and austerity: beyond work and slow death. Disability \& Society, 29(6), pp. 980-984, DOI: 10.1080/09687599.2014.920125.

Green, D. (2012). Britain welcomes brightest and best workers. Gov.UK, 4th April.

Hughes, B. (2017). Impairment on the move: the disabled incomer and other invalidating intersections. Disability \& Society, DOI: 10.1080/09687599.2017.1298991

Hughes, B. (2009). Wounded/monstrous/abject: a critique of the disabled body in the sociological imaginary, Disability \& Society, 24:4, 399-410, DOI: 10.1080/09687590902876144

Hughes, B. (2002). Bauman's Strangers: Impairment and the invalidation of disabled people in modern and post-modern cultures, Disability \& Society, 17:5, 571-584, DOI: $10.1080 / 09687590220148531$

Huijg, D.D. (2018). Brexit and its impact on disabled EU citizens and carers in the UK https://migrantsrights.org.uk/blog/2017/12/18/brexit-impact-disabled-eu-citizens-carers-uk/

International Organisation for Migration (2010). Migration and transnationalism: opportunities and challenges.

Available

from:

https://www.iom.int/jahia/webdav/shared/shared/mainsite/microsites/IDM/workshops/migration and transnationalism 030910/background paper en.pdf

Inclusion London (2017). Increase in hate crimes revealed by government figures. Available here: https://www.inclusionlondon.org.uk/campaigns-and-policy/act-now/increase-hate-crimes-revealedgovernment-figures/

Inglehart \& Norris (2016). Trump, Brexit, and the Rise of Populism: Economic Have-Nots and Cultural Backlash. HKS Working Paper No. RWP16-026. doi.org/10.2139/ssrn.2818659

Kennedy, S. (2014). Measures to limit migrants' access to benefits. The House of Commons Library. Standard notes SN06889. Retrieved from: http://www.parliament.uk/business/publications/research/briefing-papers/SN06889/measures-tolimit-migrants-access-to-benefits

Kentish, B. (2017). Philip Hammond claims disabled people finding jobs is partly responsible for UK's falling productivity. The Independent, 6 th December.

Khaleeli, H. (2015). Immigration Street: the road that sent Channel 4 packing. The Guardian, $8^{\text {th }}$ February.

Klein, N. (2017). No is not enough. Defeating the new shock politics. New York: Allen Lane.

Lewis, H., Dwyer, P., Hodkinson, S. \& Waite, L. (2014). 'Hyper-precarious lives: Migrants, work and forced labour in the Global North', Progress in Human Geography, 39(5).

Lewis, K.R. (2014). Refugee figures exceed 50 million for first time since World War II. The Parliament, 20th June.

Liddiard, K. (2018). The Intimate Lives of Disabled People. Oxon: Routledge. 
Linton, S. (1998). Claiming Disability: Knowledge and Identity. New York: New York University Press.

McNeill, J., Scullion, L., Jones, K. \& Stewart, A. (2017). Welfare conditionality and disabled people in the UK: claimants' perspectives. Journal of Poverty and Social Justice, 25(2), pp. 177-180. doi:10.1332/175982717x14943392083755.

Mallett, R. \& Runswick-Cole, K. (2014). Approaching Disability. Oxon: Routledge.

Martin, P., Scullion, L. and Brown, P. (2017). 'We don't rely on benefits': challenging mainstream narratives towards Roma migrants in the UK. Social Policy Review, 29, pp.199-217.

Matthews, P., Netto, G. \& Besemer, K. (2012). 'Hard-to-Reach' or 'Easy-to-Ignore'? A rapid review of place-based policies and equality. University of Stirling.

Mazars Report (2015). Independent review of deaths of people with a Learning Disability or Mental Health problem in contact with Southern Health NHS Foundation Trust April 2011 to March 2015

Mencap (2007). Death by indifference. Available here: http://www.hscbereavementnetwork.hscni.net/wp-content/uploads/2014/05/Death-byIndifference-Mencap-March-2007.pdf

Monbiot, G. (2017). How did we get into this mess? Politics, equality, nature. London: Verso

Nowicka, M. \& Ryan, L. (2015). Beyond Insiders and Outsiders in Migration Research: Rejecting A Priori Commonalities. Forum Qualitative Sozialforschung / Forum: Qualitative Social Research, 16(2).

O'Brien, C, (2016), 'Civis capitalist sum: class as the new guiding principle of EU free movement rights', Common Market Law Review, 53, 937-978.

O'Brien, C, (2013), 'From safety nets and carrots to trampolines and sticks: national use of the EU as both menace and model to help neoliberalize welfare policy', in D. Schiek [ed] The EU Economic and Social Model in the Global Crisis, Farnham, Ashgate, 93-114.

Papworth Trust, (2018). Disability in the United Kingdom: 2016 facts and Figures. Available from: http://online.flipbuilder.com/afjd/uvad/mobile/index.htm|\#p=1

Papworth Trust, (2016). Disability in the United Kingdom: 2016 facts and Figures. Available from: www.papworthtrust.org.uk/sites/default/files/Disability\%20Facts\%20and\%20Figures\%202016.pdf

Parsons, T. (1951). The Social System. London: Routledge and Kegan Paul Ltd.

Pisani, M. \& Grech, S. (2015). Disability and Forced Migration: Critical Intersectionalities. Disability and the Global South, 2(1), pp. 421-441.

Quarmby, K. (2011). Scapegoat: why we are still failing disabled people. London: Portobello Press.

Quinn, N. (2014). Participatory action research with asylum seekers and refugees experiencing stigma and discrimination: the experience from Scotland. Disability and Society, 29 (1), pp. 58-70. DOI:10.1080/09687599.2013.769863

Ravenstein, E.G. (1885). The Laws of Migration. Journal of the Statistical Society of London, 48(2), pp. 167-235. 
Roberts, K. \& Harris, J. (2002). Disabled people in refugee and asylum-seeking communities in Britain. Joseph Rowntree Foundation Reports, available from: https://www.jrf.org.uk/report/disabled-people-refugee-and-asylum-seeking-communities-britain

Romocea, O. (2014). Ethics and Emotions: A Migrant Researcher Doing Research among Romanian Migrants. Sociological Research Online, 19(4). doi.org/10.5153/sro.3489

Runswick-Cole, K. (2016) Understanding this thing called autism. In Runswick-Cole, K., Mallett, R. \& Timimi, S. (eds), Re-thinking autism: disability, equality, identity, pp. 19-29.London: Jessica Kingsley Publishing.

Russell, M. \& Malhotra, R. (2002). Capitalism and Disability. Socialist Register, vol 38.

Ryan, F. (2013). On Benefits and Proud: The show where 'deserving taxpayers' stalk 'proud benefit claimants'. New Statesman, 15th October.

Ryan, S. (2017). Justice for Laughing Boy, Connor Sparrowhawk - A Death by Indifference. London: Jessica Kingsley Publishers

Scullion L. \& Pemberton S. (2010) Exploring migrant workers motivations for migration and their perceived contributions to the UK: A case study of Liverpool. Salford: University of Salford.

Sharman, J. \& Jones, I. (2017). Hate crimes rise by up to 100 per cent across England and Wales, figures reveal. The Independent, 15th February.

Shakespeare, T. (2006). Disability rights and wrongs. Oxon: Routledge.

Sherry, M. (2004). Overlaps and contradictions between queer theory and disability studies, Disability \& Society, 19(7), pp. 769-783, DOI: 10.1080/0968759042000284231

Soldatic, K., Somers, K., Buckley, A. \& Fleay, C. (2015). 'Nowhere to be found': disabled refugees and asylum seekers within the Australian resettlement landscape. Disability and the Global South, 2(1), pp. 501-522.

Soldatic, K. \& Chapman, A. (2010). Surviving the Assault? The Australian Disability Movement and the Neoliberal Workfare State. Social Movement Studies, 9(2), pp. 139-154. dOI: $10.1080 / 14742831003603299$

Spencer, I.R.G. (1997). British immigration policy since 1939. The making of multi-racial Britain. London: Routledge.

Taylor, G. (2017). Understanding Brexit. Why Britain voted to leave the European Union. Bingley: Emerald Publishing Limited.

Wood, Landry \& Bloomfield (2006). Cultural diversity in Britain. Joseph Rowntree Foundation. Available from: https://www.jrf.org.uk/sites/default/files/jrf/migrated/files/1922-cultural-diversitybritain.pdf

Vargas-Silva, C. \& Rienzo, C. (2017). Migrants in the UK: An Overview. Oxford Migration Observatory. http://www.migrationobservatory.ox.ac.uk/resources/briefings/migrants-in-the-uk-an-

overview/\#kp1 
Yeo, R. (2017). The deprivation experienced by disabled asylum seekers in the United Kingdom: symptoms, causes, and possible solutions, Disability \& Society, 32:5, 657-677, DOI: 10.1080/09687599.2017.1320268 
Appendix 1 - Sketch from the xxxx event by $x x x x$

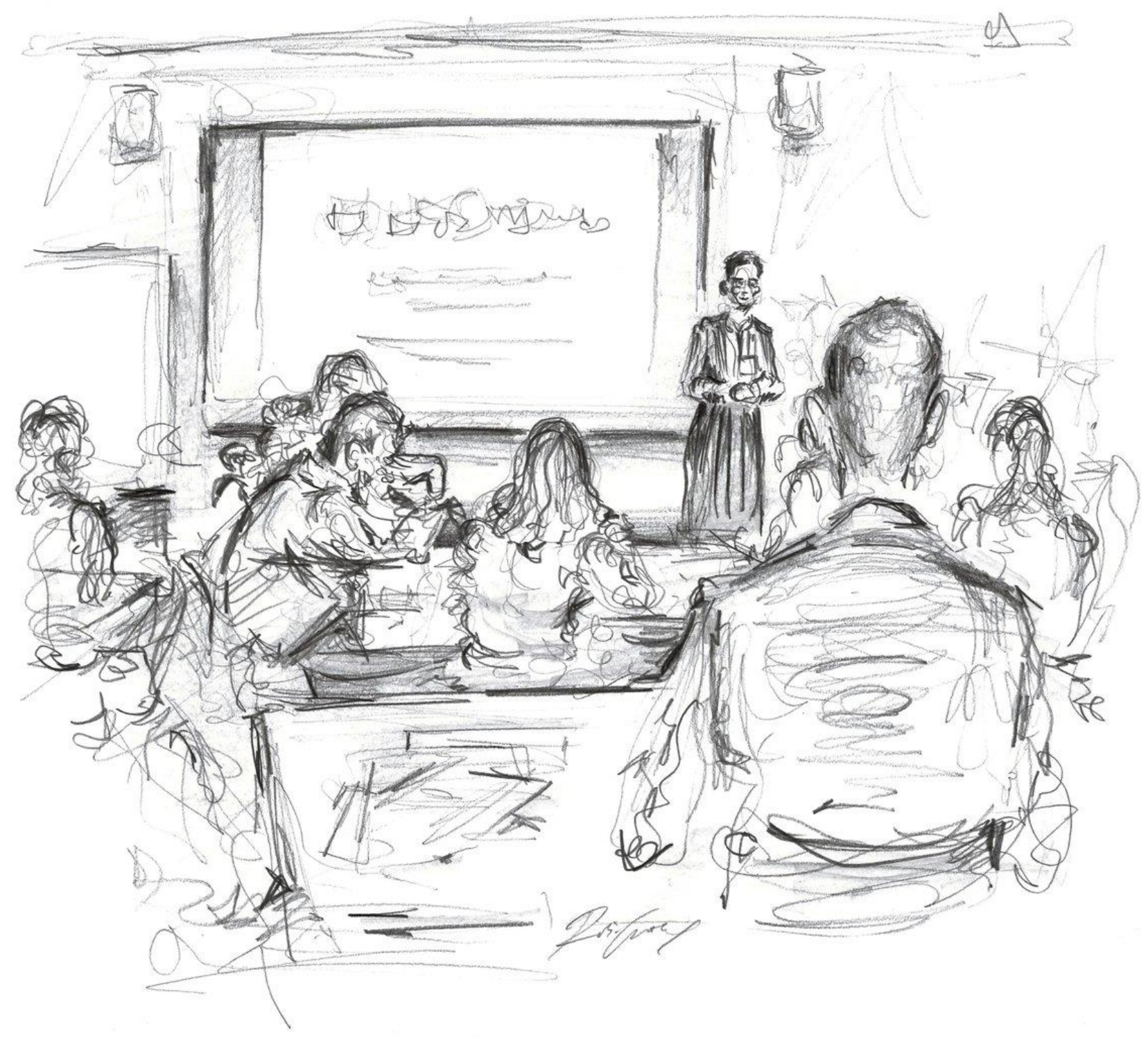


Appendix 2 - Sketch from the $x x x x$ event by $x x x x$

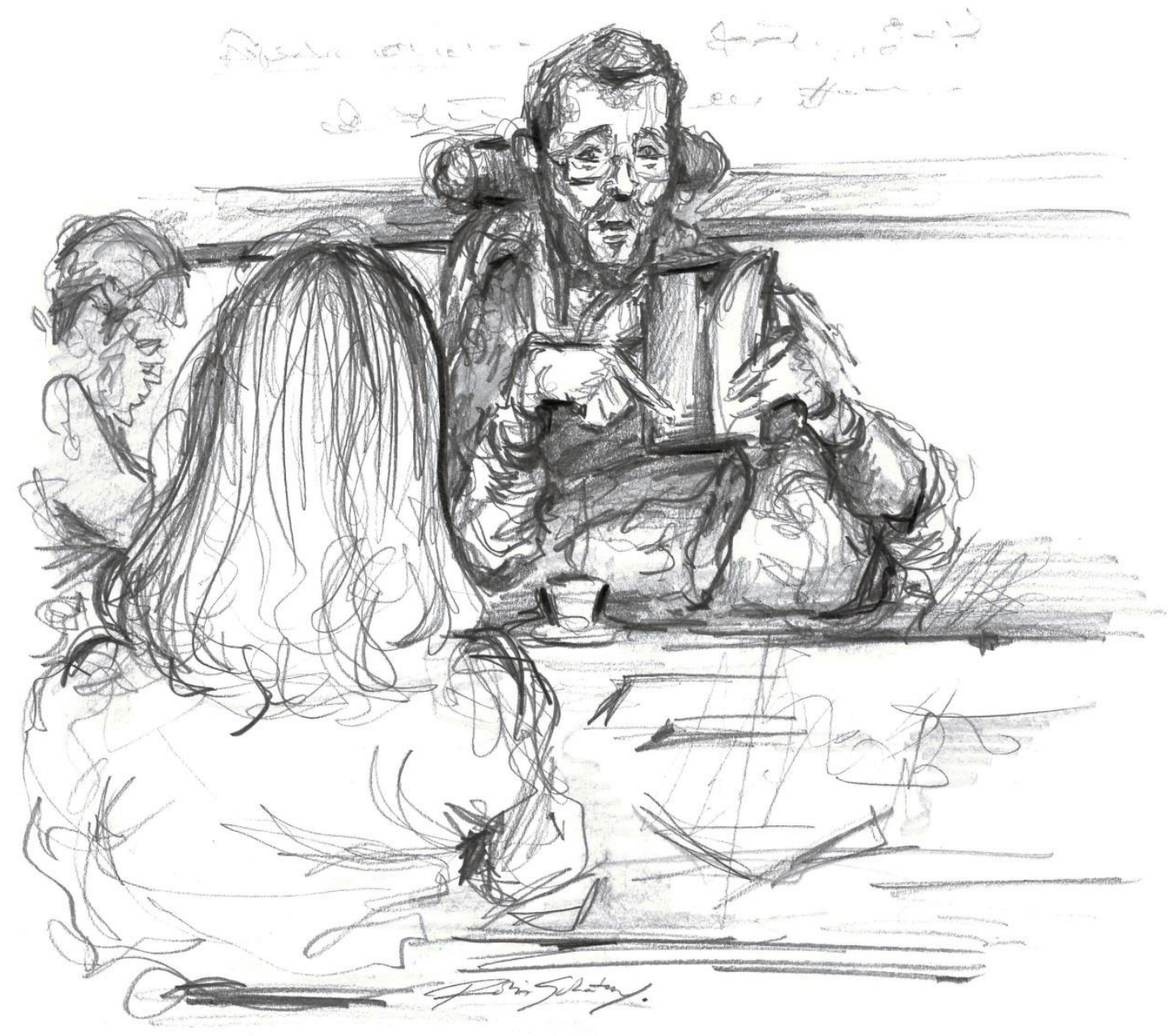

